\title{
Drawing the line on physician-assisted death
}

\author{
Lynn A Jansen, ${ }^{1}$ Steven Wall, ${ }^{2}$ Franklin G Miller ${ }^{3}$
}

${ }^{1}$ The Center for Ethics in Health Care, Oregon Health \& Science University, Portland, Oregon, USA

${ }^{2}$ Philosophy, University of Arizona, Tucson, Arizona, USA ${ }^{3}$ Weill Cornell Medical College, New York City, New York, USA

\section{Correspondence to} Dr Lynn A Jansen, The Center for Ethics in Health Care, Oregon Health \& Science University, Portland, OR 97239, USA: jansen@ohsu.edu

Received 11 June 2018 Revised 10 October 2018 Accepted 27 October 2018 Published Online First 21 November 2018

\section{Check for updates}

(C) Author(s) (or their employer(s)) 2019. No commercial re-use. See rights and permissions. Published by BMJ.

To cite: Jansen LA, Wall S, Miller FG. J Med Ethics 2019;45:190-197.

\section{ABSTRACT}

Drawing the line on physician assistance in physicianassisted death (PAD) continues to be a contentious issue in many legal jurisdictions across the USA, Canada and Europe. PAD is a medical practice that occurs when physicians either prescribe or administer lethal medication to their patients. As more legal jurisdictions establish PAD for at least some class of patients, the question of the proper scope of this practice has become pressing. This paper presents an argument for restricting PAD to the terminally ill that can be accepted by defenders as well as critics of PAD for the terminally ill. The argument appeals to fairness-based paternalism and the social meaning of medical practice. These two considerations interact in various ways, as the paper explains. The right way to think about the social meaning of medical practice bears on fair paternalism as it relates to PAD and vice versa. The paper contends that these considerations have substantial force when directed against proposals to extend PAD to non-terminally ill patients, but considerably less force when directed against PAD for the terminally ill. The paper pays special attention to the case of non-terminally ill patients who suffer from treatment-resistant depression, as these patients present a potentially strong case for extending PAD beyond the terminally ill.

Physician-assisted death (PAD) continues to be a contentious issue in many legal jurisdictions across the USA, Canada and Europe. PAD is a medical practice that occurs when physicians either prescribe or administer lethal medication to their patients. ${ }^{i}$ As more legal jurisdictions establish PAD for at least some class of patients, the question of the proper scope of this practice has become pressing. We consider whether a legal option of PAD should be limited to terminally ill patients in the jurisdictions where it has been established. In considering this issue we do not take a stand on whether PAD should be established in the first place. Our question is conditional. If PAD is legalised in a given jurisdiction, should it be limited to terminally ill patients? We seek to identify general reasons for limiting PAD to the terminally ill. Naturally, if one is opposed to PAD in all cases, then one will oppose its extension beyond terminal illness in jurisdictions where it has been established. But we seek to identify reasons for restricting PAD that can be accepted by defenders as well as critics of PAD for the terminally ill.

We do not consider in any detail existing law as it bears on PAD. Laws vary from jurisdiction to jurisdiction. Our question is not what the law on PAD is,

${ }^{\mathrm{i}}$ There are important differences between the former (assisted suicide) and the latter (active euthanasia), but these differences will not be important to our discussion. or ought to be, in this or that region of the world, but rather on what legal options for PAD should be permitted, if PAD has been extended to the terminally ill. In limiting our discussion in this way, we do not deny that adequate recommendations for policy change concerning PAD in particular countries must take account of the legal situation in those countries. But our discussion aims to be broader and to focus on the ethics of policy and practice with respect to $\mathrm{PAD}$.

The normative question of the proper scope of the legal option to PAD has been taken up by others. ${ }^{1-5}$ Although PAD is limited to the terminally ill in the USA in the several states where it has been legalised, in some countries, such as the Netherlands, Belgium and Switzerland, PAD is not currently limited to the terminally ill. Moreover, in several European countries, there appears to be substantial public support for extending PAD even further. The momentum appears to be on the side of allowing PAD for a broader range of patients. Nevertheless, we seek here to present some new considerations that tell in favour of confining PAD to the terminally ill. ${ }^{\text {ii }}$ The considerations in question concern fair paternalism and what we will refer to as the social meaning of medical practice. These twin considerations interact in various ways, as we will be explaining. The right way to think about the social meaning of medical practice bears on fair paternalism as it relates to PAD and vice versa. We contend that these considerations have substantial force when directed against proposals to extend PAD to non-terminally ill patients, but considerably less force when directed against PAD for the terminally ill.

In arguing that PAD should be limited to the terminally ill, we adopt the stance of the various jurisdictions in the USA that define terminal illness in terms of a prognosis of dying from a medical condition within 6 months or less. This standard also coincides with established criteria of eligibility for hospice services. Admittedly, there is an element of arbitrariness in this standard, given uncertainty in making prognostic judgments for patients with various life-threatening medical conditions. Nevertheless, any legal option of PAD for the terminally

${ }^{i i}$ For example, in Canada, where PAD became legalised in 2016, it is available for patients with a 'grievous medical condition' and 'whose natural death has become reasonably foreseeable' (see Li $e t a l^{27}$ ). This seems clearly to include some patients who are not terminally ill. And advocates in Oregon are endeavouring to expand the criteria beyond terminal illness to include patients with a variety of degenerative conditions (see Kuznia ${ }^{28}$ ).

iii Anticipations of our argument can be found in Pickering Francis ${ }^{29}$ and Kim and Lemmens, ${ }^{15}$ although neither of these discussions develop a general normative framework that appeals to group-based fair paternalism. 
ill must provide some guidance to clinicians regarding eligibility. As a matter of convenience and following precedent, we endorse the 6 months or less standard here.

\section{DISTINGUISHING CASES}

Non-terminally ill patients form a large and disparate class. So, it is necessary to distinguish different groups within the class. We will discuss three groups in some detail. These groups do not exhaust the possibilities. There are non-terminally ill patients who do not fit under any of them. Since not every salient group of non-terminally ill patients can be discussed in a paper of this size, our contention that the legal option to PAD should not be extended to those who are not terminally ill rests on the defeasible assumption that the arguments we present apply with appropriate modifications to the groups of non-terminally ill patients that we do not discuss. Having noted this limitation to our argument, we want to emphasise that the groups that we focus on raise fundamental issues about the scope of PAD, and two of them have been the object of debate in some of the jurisdictions that have established PAD for the terminally ill. The discussion of the third group, which consists of non-terminally ill patients who appear to suffer from depression that is treatment-resistant and who wish to end their lives as a means to ending their suffering, is central to the argument of this paper. This group of patients presents what many consider to be the strongest case for extending PAD beyond the terminally ill. However, we begin our analysis with the other two groups, the first of which is not pressing, as virtually no one favours extending PAD to them.

The first group consists of young adult patients who do not suffer from any grave illness, physical or mental, but nonetheless wish to end their lives with the assistance of a physician. Consider a 22-year-old patient with a medical condition that is not life-threatening, such as type 1 diabetes, who desires to end her life because of a recent romantic break-up. Such a person does not suffer from a grave illness, even if she is currently experiencing a high level of anguish. There are very few patients of this kind, and no legal jurisdiction that we are aware of grants them access to PAD. Yet, while the exclusion of such patients from PAD is not controversial, attention to the considerations that support this exclusion will prove to be instructive. Indeed, in seeking to identify where to draw the line on PAD, one should first consider whether any line must be drawn at all.

Note first that if a young adult of this kind needed some treatment-for example, an injection of insulin - to continue living, then she could refuse this life-sustaining treatment, provided that the patient is deemed competent and making a voluntary, autonomous decision. She would have a legal option to do so in countries that recognise a general legal right to refuse unwanted medical treatment. And, arguably, she would have a moral right to do so. ${ }^{\text {iv }}$ Yet, if one has a right to refuse life-sustaining treatment, then why does one not also have a claim to assistance in dying by means of access to lethal medication? Both the refusal of life-sustaining treatment and the decision to undergo PAD can be an autonomous decision by patients to end their lives. ${ }^{v}$ Furthermore, defenders of PAD often boldly assert that

\footnotetext{
${ }^{\mathrm{iv}}$ The WHO maintains that the human right to healthcare includes a right to refuse non-consensual medical treatment (see www.who.int/newsroom/fact-sheets/detail/human-rights-and health). The European Court of Human Rights (Haas v Switzerland, 2014) has held that patients have a right to determine the time and manner of their death. This does not imply that they have a right to the assistance of others in terminating their lives.
}

${ }^{\mathrm{v}}$ See Brock. ${ }^{7}$ autonomy takes precedence over well-being. 'In the case of competent patients', it is proclaimed, 'autonomy trumps wellbeing' (Steinbock, p34). .vi $^{2 \mathrm{p}}$

It is important to identify where this line of argument goes wrong. There are significant differences between a legal right to refuse life-sustaining medical treatment and a legal right to PAD. These differences explain how it is consistent and reasonable to grant that young and otherwise healthy patients have a legal right to refuse life-sustaining treatment and deny that they have a claim to have a legal option to PAD. One such difference is that PAD requires the assistance of a physician. Although all physicians must respect the rights of patients to refuse medical treatment, no physician has a duty to participate in PAD. A second difference is that refusing life-sustaining treatment is grounded in a strong negative right of bodily integrity that protects people from non-consensual intrusions on their bodies. Just as medical treatments for competent patients are permissible only with their informed consent, so too the refusal of life-sustaining treatment by a competent patient must be honoured. PAD, by contrast, involves a request by a patient for a lethal medical intervention, rather than a refusal of unwanted medical treatment. ${ }^{6}$ Presuming that there is a positive right to medical treatment, it is far from clear that its scope includes access to lethal medical interventions, especially for patients who are not terminally ill.

It can be countered that all patients with decision-making capacity should have the legal option to engage in PAD provided that they are able to find physicians who are willing to assist them. This is the position of some writers who are strongly opposed to paternalism. ${ }^{\text {vii }}$ But for young healthy patients, almost all physicians would refuse to do so, and rightly so. They would refuse to do so because they would judge that PAD is not in the best interests of these patients. Proponents of PAD sometimes express scepticism about our ability to judge objectively whether or not PAD is in the best interests of the patients who seek it. As one writer puts it, 'there is no objective standard, but only the competent patient's judgment of whether continued living is no longer a benefit' (Brock, p11). ${ }^{7 v i i i}$ But applied to young non-terminally ill patients, like the one described above, this statement seems patently false. We can be confident that these patients are making a mistake, as they very likely have many years of healthy life ahead of him.

Physicians would resist participating in PAD for such patients for another reason as well. They would suspect that these patients would in many cases change their minds. If we do not help them to end their lives now, then many of them would endorse our refusal to do so later when they were feeling better. With respect to terminally ill patients, matters are different. As their life expectancy is short, for them, it is much harder for others to determine where their best interests lie. We also have much less reason to think that these patients would change their minds later if physicians refused to aid them now.

These points show that the bold claim that autonomy trumps well-being and the sceptical claim that we must defer to the wishes of patients, since there is no objective method for determining whether continued living is beneficial to them, if true

\footnotetext{
${ }^{\text {vi }}$ See also Feinberg. ${ }^{30}$

${ }^{\text {vii }}$ See, for example, Feinberg. ${ }^{30}$ For effective criticism of Feinberg's strong antipaternalist stance, which itself invites the reader to consider the case of suicide for a young adult, see Arneson. ${ }^{31}$

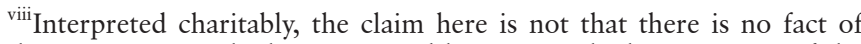
the matter as to whether continued living is in the best interests of the patient, but rather that there is no objective method for ascertaining the fact.
} 
at all, are true only for some subset of patients who might seek PAD. The points also show that there is no sweeping fundamental moral right to determine with the assistance of others the time, circumstances and manner of one's death. These conclusions should be borne in mind as we consider cases that are more controversial than those that involve young adults who suffer from no life-threatening or debilitating illness.

We turn now to a second group of non-terminally ill patients. They are elderly, but they do not suffer from either a terminal illness or from major depression. Nevertheless, they feel that 'their life is completed' and that continued life is not worth living. ${ }^{8}$ They are, as it is sometimes put, 'tired of life'. Consideration of this group of patients is a natural next step in our discussion. For a key difference between young adults and tired of life patients is proximity to death. Tired of life patients are not terminally ill, but, unlike young adults, they do not have the prospect of decades of life ahead of them.

Tired of life patients wish to end their lives not because they suffer intolerably from an underlying physical or mental illness, but because they no longer find life meaningful or worth living. ${ }^{8}$ Typically, such patients have various physical ailments associated with growing old, but it is their existential concerns that primarily motivate their desire for death. These existential concerns can be quite serious and their significance should not be minimised. ${ }^{\text {ix }}$ Tired of life patients often experience isolation and loneliness, worry about losing their independence and dignity, and fear becoming a burden for loved ones. ${ }^{\text {ix }}$

PAD for tired of life patients has become an issue in the Netherlands. The majority of physicians in the Netherlands, and elsewhere, oppose PAD for these patients, ${ }^{9}$ but a growing segment of the Dutch population appears to favour giving elderly people who do not have a grave or life-threatening medical condition but are tired of living the legal option to end their lives. ${ }^{10 \mathrm{x}}$

Limiting PAD to the terminally ill is plainly more controversial when this group of patients, in contrast to young adults, is the contrast class. Elderly people have much less life in prospect than younger people. If they make a mistake in ending their lives, then the mistake will be less serious than if a younger person makes it. Further, it is not as likely that elderly patients, when compared with younger patients, will change their minds about the worthwhileness of continued life. Older people tend to be more settled in their preferences and values than younger people. Finally, and more contentiously, it is often thought life is less valuable when one has reached advanced old age. The deteriorating effects of ageing diminish the capacity to enjoy life and make valuable contributions to the world. Many tired of life patients compare their present condition with how they used to be, and many decry their decreasing ability to contribute to the lives of others. ${ }^{10}$

This last point may reflect problematic social attitudes about ageing and the aged. We return to this challenging issue later. For now, we mention an important consideration that bears on the issue of whether the legal option to PAD should be extended to tired of life patients. This concerns what we will call the social meaning of the role of a physician. This social meaning comprises both the self-understanding of physicians and how the wider society views them. The role of a physician, as expressed in a range of codes and documents, is to promote health and

\footnotetext{
${ }^{\text {ix }}$ The underlying cause of suffering should be distinguished from its nature and severity. From the fact that a patient's suffering is not caused by a grave physical or mental illness, it does not follow that it is not severe.

${ }^{\mathrm{x}}$ See also Onwuteaka-Philipsen et al. ${ }^{32}$
}

thus to preserve and enhance human life. Physician involvement in PAD either for young adults or for older tired of life patients is straightforwardly inconsistent with this understanding of the role of a physician. In contrast with terminally ill patients, and possibly in contrast with some patients who suffer from treatment-resistant severe depression, patients in these groups are not the victims of a physical or mental disease for which treatment has become futile. To be sure, clinicians disagree over whether interventions to intentionally hasten death are ever necessary to adequately treat pain or suffering. We do not take a stand here on this contested issue. Yet, however the issue is resolved, the social meaning of the role of physicians helps to explain why jurisdictions that recognise a right to PAD almost always limit it to cases in which it is considered a last resort measure in response to an untreatable illness.

To be sure, the social meaning of the role of a physician is subject to change, and those who wish to extend PAD to tired of life patients can argue that the social meaning of this role should be adjusted to reflect the changing attitudes of new populations. However, this is a matter that potentially affects all patients, and not just those patients who desire to end their lives. This is why we have formulated it in terms of its social meaning as opposed to the more common formulation that emphasises the rolebased duties of individual physicians. ${ }^{\mathrm{xi}}$ In considering whether a change in the social meaning of the role of a physician is desirable, one needs to attend to more than the self-understandings of individual clinicians and the desires of their patients. One also must consider how this change would affect patients generally, and since its effects on some patients could be different from its effects on others one must consider how to balance these when they conflict. This social dimension of the debate over the proper scope of PAD is overlooked by those who focus exclusively on the purported right of adult patients to control the timing and manner of their death. As will become apparent, it also links the social meaning of a physician's role to the fair paternalism argument that we will be presenting shortly.

The final group of non-terminally ill patients that we want to consider consists of those who are not terminally ill and do not have a life-threatening physical illness, but who suffer from depression that so far has proven resistant to treatment. The severity of the depression suffered by these patients, and its apparent resistance to treatment, makes this group of patients a potentially strong case for extending the legal option to PAD beyond the terminally ill. This group of patients has been much discussed in the recent literature on PAD, more so than groups of patients who suffer from other treatment-resistant illnesses for which PAD might be requested, such as schizophrenia and bipolar disorder. This explains our focus on them here.

In some legal jurisdictions, patients diagnosed with treatment-resistant depression already have been given the legal option to PAD. The option is limited to patients who experience suffering that is considered to be 'unbearable', and assisted death must be judged to be the only available means for addressing it (Schuklenk and van de Vathorst, p579). ${ }^{1}$ Still, public support for extending PAD to patients with treatment-resistant depression is not strong (Schuklenk and van de Vathorst, p577). ${ }^{1 \times i i}$ This may reflect a failure on the part of the public to understand fully the severity of the suffering that is associated with major forms of depression (Schuklenk and van de Vathorst, p578). ${ }^{1}$ Yet even

\footnotetext{
${ }^{x i}$ For a statement of the latter view, see Pellegrino. ${ }^{33}$

xii But see the Third Evaluation Report of the Euthanasia Law, where public support for PAD for patients with severe depression was reported to be $58 \%$.
} 
granting the severity of the suffering in question, the case for extending PAD to this group of patients is far from straightforward. Some writers have claimed that it is unfair discrimination to allow PAD for terminally ill patients, but not for patients with severe depression, if both groups of patients experience untreatable and unbearable suffering (Schuklenk and van de Vathorst, $\mathrm{p} 577^{1}$; Steinbock, $\mathrm{p} 32^{2}$ ). This complaint has force, however, only if there are no relevant differences between these two groups of patients. Three important differences stand out. First, non-terminally ill patients with depression are in general in a better position than terminally ill patients to end their lives themselves. This situation, to be sure, is not ideal. But it undercuts the claim that without PAD for such people they literally would have no options to escape their suffering, and that they would be in effect 'locked in a harsh prison ward with their unbearable pain [with] no way to escape it'. ${ }^{11}$ (We return to this point below in discussing the option of voluntary stopping eating and drinking.) Second, it is widely acknowledged that depression poses a threat to decision-making competence in a way that non-psychiatric illnesses do not. Third, the identification and characterisation of treatment-resistant depression are fraught with difficulty. Many patients with depression who are identified as treatment-resistant are in fact 'pseudo-resistant'. ${ }^{12}$ Patients considered to be treatment-resistant may have received inadequate dosing of antidepressant medication, the primary cause of their depression may have been misidentified, or they may have failed to comply with appropriate medication guidelines, for example.

The uncertainty surrounding treatment-resistant depression, an uncertainty that is greater than that associated with the assessment of patients as terminally ill, is relevant to the question of whether PAD should be an option for patients suffering from, or appearing to suffer from, treatment-resistant depression. Nevertheless, presumably there remain patients who are correctly diagnosed with treatment-resistant depression and who genuinely wish to end their lives as a means to combating their suffering. If such patients are denied PAD, while terminally ill patients are given this option, the concern about discrimination will remain. Some will insist that if even one competent patient suffering from treatment-resistant depression is denied the option to PAD, then a serious injustice has been done (Steinbock, p36). ${ }^{2 x i i i}$

\section{GROUP PATERNALISM AND FAIRNESS}

We think that this is a mistake. A key issue in deciding the proper scope of a legal option of PAD is under what conditions, if any, individuals have a fundamental right to physician assistance in determining the timing and circumstances of their death. We argued above that a sweeping view of a right to PAD based on individual autonomy is unsound, as it would permit healthy adults to end their lives with physician assistance. Do individuals suffering from treatment-resistant depression have a strong claim to a legal right to PAD? We argue against recognition of such a right by invoking a conception of fairness-based (legitimate) paternalism. We will focus on patients with treatment-resistant depression, but if the argument works for them, then it likely applies to tired of life patients as well.

Paternalistic interventions aim to protect people from defective decisions. In contemporary medical ethics, paternalism has a bad name. The modern emphasis on respecting patient

\footnotetext{
xiii See also Dembo et al. ${ }^{34}$

autonomy is rightly viewed as a significant advance over the days when physicians made treatment decisions without consulting the wishes of their patients. But there are better and worse forms of paternalism, and the kind of paternalism that we defend here engages considerations of fairness that must be considered by any acceptable policy on PAD. ${ }^{\text {xiv }}$

How should fair paternalism be understood in relation to PAD? We propose that paternalistic restrictions on PAD are justified on the grounds that they prevent two kinds of mistakes. These occur when either (1) patients engage in PAD when they lack the decision-making competence to do so, and/or (2) patients engage in PAD when doing so is not in their best medical interests. These mistakes are avoided when patients, with decision-making competence, engage in PAD and by doing so further, or at least do not set back, their interests.

The claim that patients should not have the option to PAD if they lack decision-making competence is not controversial. It is a legal requirement for PAD in all the jurisdictions that permit it. Restrictions on PAD designed to ensure that mistakes concerning decision-making competence are avoided can be characterised as soft paternalism. And the legitimacy of soft paternalism is widely granted even by those who otherwise oppose paternalism. The claim that patients should not have the option to PAD if doing so is not in their best medical interests, even if they have decision-making competence and could make an autonomous decision to opt for it, is controversial, however. Restrictions on PAD designed to guard against this kind of mistake can be characterised as hard paternalism. ${ }^{\mathrm{xv}}$ And the legitimacy of hard paternalism is often denied. Shouldn't patients have an option to make a self-determining choice about a matter of this importance, even if they make a decision that runs counter to their interests?

Yet PAD is not simply patient suicide, but physician-aided suicide. To determine the legitimacy of restrictions on PAD, we need to consider how different regulatory schemes affect the interests of different patients. The scope of PAD is a question of public policy because the practice involves the prescription or administration of a lethal intervention by professionals who are licensed by the state to serve the best interests of vulnerable patients. Whether individual patients should have a legal right to PAD depends on whether a well-considered policy would grant them the right. Well-considered policies must be responsive to the interests of all affected parties and to the significant practical uncertainties that attend the identification of their interests.

We will return to this point in a moment. But first we highlight a supporting point. Earlier we claimed that the role of physicians has a social and, we can now add, a fairness-based dimension. Under the current social meaning, physicians have duties not to harm their patients. As we have acknowledged, this social meaning could change. Physicians could be permitted to impose harm on their patients, so long as their patients consented to it. This dramatic change in the role of physicians, we believe, would expose countless vulnerable patients to harms that it is unfair to impose on them. If we are right about this, then there is a reason of fairness to conserve the current social meaning of

\footnotetext{
${ }^{x i v}$ For an important general statement of fairness-based paternalism, see Arneson. ${ }^{35}$ For an application of the argument to the context of clinical research, see Jansen and Wall. ${ }^{36}$

${ }^{\mathrm{xv}}$ More precisely, the hard paternalism in question is what Feinberg classifies as indirect hard paternalism, since it involves two parties (the physician and the patient) and the restrictions are imposed on one party (the physician) for the sake of protecting the other party (the patient). See Feinberg, pp9-10. ${ }^{30}$
} 
medicine, and this current meaning supports the policy-based paternalism that is involved in holding that a justified instance of PAD must satisfy the best interests condition as well as the decision-making competence condition.

Some will object that, for any particular patient, if all the relevant conditions are satisfied, then paternalistic interventions that preclude the legal option to PAD for that patient would be unjustified. This is an inference that we wish to challenge. It is a mistake, and a common one in the literature on PAD, to focus attention too much on the ideal case, where no mistake is in prospect and all uncertainties have been resolved. For if the ideal case is not representative of the kinds of cases that will be affected by the policy, then it will tell us little about whether the policy is well considered. Paternalistic restrictions on PAD, for this reason, must be group-centred and based on a realistic assessment of the situation. They must aim to prevent mistakes among a group of representative patients in contexts where it is not known with sufficient confidence which individual members of the group would make mistakes or would be inclined to do so. For reasons mentioned above, when the group of patients under consideration are those that have been diagnosed as suffering from treatment-resistant depression, the likelihood of mistake is high. Since this point is important to our argument, we now add some further considerations in support of it.

Although a significant number of patients who suffer from major depressive disorder have been classified as treatment-resistant (some estimates put this as high as $30 \%$ ), there is no clinical consensus on the criteria for this diagnosis. 'A correct determination of what constitutes [treatment-resistant depression] requires consensus on criteria of treatment response (ie, dose, duration, and compliance) and on the number of adequate trials required before a patient is determined to be nonresponsive'. ${ }^{12}$ But no such consensus currently exists. Patients with depression who are diagnosed as treatment-resistant by some criteria will not be so diagnosed by others.

A tempting response to this problem is to stipulate a set of clinical criteria for a determination of treatment-resistant depression. ${ }^{\text {xi }}$ But stipulating criteria requires defence. If there is no expert consensus on the criteria, why should they, as opposed to other criteria, be assumed in thinking about whether PAD should be extended to this class of patients? Moreover, the designation 'treatment-resistant' is potentially misleading. To many it will suggest that the patient cannot be helped by treatment. However, for clinicians who study and treat depression, the designation is not meant to imply that treatment-resistant patients cannot be helped by appropriate treatment. Indeed, once a patient with depression has been diagnosed as treatment-resistant, there emerges an important clinical question. What form of treatment is optimal for her? ${ }^{13}$

\footnotetext{
${ }^{\mathrm{xv}}$ For example, one could stipulate that 'a patient is considered therapy resistant when consecutive treatments with 2 products of different classes, used for a sufficient length of time at an adequate dose, fail to introduce an acceptable effect'. The European Agency for the Evaluation of Medicinal Products Committee for Proprietary Medicinal Products. Note for guidance on clinical investigation of medicinal products in the treatment of depression. Available at http://www.emea.eu.int/pdfs/human/ ewp/051897en.pdf. (Note that stipulations, such as this one, still leave vagueness or indeterminacy in place, since clinicians can be expected to disagree over what counts as a sufficient length of time, what qualifies as an acceptable dose and what constitutes an acceptable effect.) (Sourey et al, 'Treatment-Resistant Depression,12) Further, this criterion might work well in defining 'treatment resistant' for the purpose of eligibility for clinical research, but it looks ill-suited for defining eligibility for the life-ending practice of PAD.
}

With these difficulties in view, one may be tempted to introduce a new category of patients with treatment-resistant depression. These are patients who have been correctly diagnosed as treatment-resistant, and have little to no probability of responding to any further treatment. This manoeuvre has the clear advantage of picking out the class of patients who intuitively have the strongest claim to have a legal option to PAD. This new category of patients will be smaller than the class of patients correctly diagnosed as treatment-resistant (on any of the major statements of the relevant criteria for this diagnosis), but the number of such patients may remain significant. The disadvantage of this manoeuvre is that it further complicates efforts to correctly identify the relevant group of patients. Not only must a diagnosis correctly identify those whose depression is treatment-resistant, but also it must correctly identify those for whom further treatment will be ineffective. And this further determination is not one that clinicians, at present, are well positioned to make.

The pertinent difficulties concerning the diagnosis of treatment-resistant depression do not show that a correct diagnosis cannot be made. But they do bring out the very substantial potential for mistake for any such diagnosis. Since the mistake in question would violate the best interests condition on acceptable instances of PAD, it is the type of mistake that well-considered restrictions on PAD should aim to prevent. Similar concerns can be raised about the decision-making competence condition. Patients with severe depression are not necessarily disqualified from making competent decisions about suicide. But, even granting this point, there remain formidable challenges in determining when depression undermines decision-making competence. Depression is a mood disorder that affects decision making, and severe depression can have a severe effect on people's ability to make decisions in line with their enduring values. This reality helps to account for why many patients with depression express unstable preferences about their treatment. ${ }^{14}$ Assessments of decision-making competence for patients with severe depression are challenging and they are often made with considerable uncertainty. In this context, one should expect mistakes to be made, even when conscientious efforts are made to avoid them.

We have been calling attention to the mistakes, and the likelihood of these mistakes occurring, that bear on the issue of whether PAD should be a legal option for those who are diagnosed with treatment-resistant depression. These mistakes can be characterised as false positive mistakes that pertain to patients who are not appropriate candidates for PAD, owing either to impaired decision-making competence or the possibility of effective interventions that can restore the patient's will to live. Systematic research on the prevalence of these mistakes in jurisdictions that have permitted PAD for these patients is not available. But scholars have expressed concern. ${ }^{15}$ As one expert explained recently, 'I'm convinced that in Belgium people have died where there were still treatment options and where there was still a chance for years and even decades of (quality) life'. ${ }^{16}$

Policies are by nature general, but they can be formulated so as to leave a great deal of discretion to the individuals who apply them. Some might favour a policy on PAD for patients with treatment-resistant depression that establishes an individualised approval process with rigorous safeguards. ${ }^{17} 18$ But given the difficulties in diagnosing treatment-resistant depression, the lack of a clear professional consensus on the criteria for such a diagnosis, and the challenges involved in determining that patients with severe depression have decision-making competence, there is little basis for thinking that individualised approval processes would be a reliable safeguard against false positive mistakes. 
There is a further point to make. Even if one were convinced that an ideal approval process could acceptably reduce the risk of false positive mistakes, one still would need to consider the currently existing approval processes in the countries in question as well as the likelihood that these processes will be significantly improved in the near future. And one would need to take seriously the possibility that the required approval process would be infeasible. With this in mind, one could accept our argument in the interim, as it were, holding that PAD should not be extended to patients with treatment-resistant depression until, and if, sufficiently rigorous and resourced approval procedures were put in place. ${ }^{18}$

A better objection to our proposal is that in highlighting the risks of false positive mistakes we have ignored another kind of mistake that is of equal or greater importance. This false negative mistake occurs when a patient is denied the option to PAD when he desires to end his life and when both the decision-making competence and best interests conditions are satisfied. This kind of mistake, the objection will continue, is guaranteed to occur under the paternalistic policy we have been proposing.

This objection once more brings out the crucial feature of the policy situation we are addressing. Any policy concerning PAD for patients with treatment-resistant depression, whether paternalistic or permissive, can be expected to benefit some patients and harm others. Under a permissive policy, some patients will be liable to the kinds of false positive mistakes we have been emphasising. Under a paternalistic policy, in contrast, some patients will be prevented from engaging in PAD when the conditions that render it acceptable are satisfied, thus giving rise to potential false negative mistakes.

While we grant that some patients with depression could have their interests set back by the policy we are recommending, the number of such patients is likely to be small. ${ }^{19}$ Moreover, it is important to get clearer on the costs involved. Defenders of extending the legal option to PAD to patients with treatment-resistant depression claim that without this option such patients have no escape from their suffering. ${ }^{11}$ But this claim is true, as we pointed out above, only if there are no other options available to these patients for ending their lives. Such options are available. Patients can and do end their lives without the assistance of physicians. Some have been unimpressed with this observation. 'It is in nobody's interest that patients (have to) resort to starving themselves to death, jumping off buildings or resorting to any number of more or less gruesome means to bring about their deaths'. ${ }^{20}$ We agree about the desirability of avoiding the gruesome means, but the option to stop eating and drinking can be a tolerable alternative to PAD, one that is available as a legally protected option in most of the legal jurisdictions that we are concerned with. ${ }^{\text {xvi }}$

Voluntarily stopping eating and drinking (VSED) raises important ethical questions for physicians that we cannot take up. ${ }^{\text {xviii }}$ But, most basically, it can be viewed as an outgrowth of the moral and legal right to refuse unwanted medical interventions. ${ }^{21}$ There are a number of advantages to the VSED option, so understood. First, it takes firm resolve to carry through with the decision. Those who are ambivalent about ending their lives will not likely succeed in doing so in this manner. Second, it can take up to several weeks, thereby giving patients considerable time to change their minds. ${ }^{22}$ This is particularly

\footnotetext{
xvii There are also illegal options for such patients, such as acquiring pentobarbital or other lethal drugs via the internet.

xviii For a variety of perspectives on VSED, see Bernat et al, ${ }^{37}$ Jansen, ${ }^{21}$ McGee and Miller, ${ }^{25}$ and Quill et al. ${ }^{38}$
}

important for patients with depression, who often change their minds about suicide. Third, the option is available to nearly all patients with depression, including those who suffer from severe physical impairments, such as quadriplegia. Fourth, it need not be especially uncomfortable for those who engage in it. When managed appropriately 'the process of VSED has generally been described as peaceful, marked by progressive weakness and decreasing alertness, with a gradual descent into somnolence and coma over the course of days to weeks'. ${ }^{23}$ Fifth, physicians need not be involved in the patient's initial decision to engage in VSED. In a recent study of VSED in the Netherlands, researchers found that only one in two family physicians were informed in advance about their patient's decision to elect VSED, and one in three had no involvement at all with the decision. ${ }^{24}$

This last point shows that VSED cannot be viewed simply as a different form of PAD. True, physicians often provide supportive care to patients who have opted for VSED. But physicians who oppose PAD for non-terminally ill patients can provide supportive care to them, as a means to relieving their physical distress, not as a means to ending their lives. ${ }^{25}$

The issues here are delicate. There is a compelling need for better care and treatment for those who suffer from severe mental illnesses, including those who suffer from depression that so far has proven resistant to standard therapy. For the reasons we have outlined, there are formidable difficulties in determining whether patients with treatment-resistant depression are genuinely beyond therapeutic help and so, in any given case, there is likely to be considerable uncertainty over whether VSED would be in the best interests of the patient. That is one reason why physicians, even those who accept the permissibility of PAD for terminally ill patients, should be very reluctant to recommend this option to patients with treatment-resistant depression. A second reason concerns the difficulty of ascertaining that the refusal of foods and fluids of a patient with depression is undertaken with capacity. If a patient lacks decision-making competence, then she cannot engage in VSED, and we have already reviewed the challenges in making determinations that patients with severe depression satisfy the decision-making competence condition. Nevertheless, VSED for patients with treatment-resistant depression is less liable to mistake than PAD for these patients, since when they have the competence to exercise their legal right to refuse food and fluids their physicians must honour this refusal, even when the physicians remain unsure whether it is in the best interests of the patients to do so.

Despite the difficulties it presents, VSED remains an option, legally protected in many jurisdictions, for patients with treatment-resistant depression. Although some patients will view this option as inferior to PAD, ${ }^{26}$ its availability reduces the costs to them of the denial of the latter option. And this point is helpful to our argument. By reducing the costs of those who would lose out under the paternalistic policy we are proposing, it makes it fairer to ask them to bear these costs, given that the alternative policy of extending PAD to patients with treatment-resistant depression would impose the costs of false positive mistakes on others that we have highlighted and given that the incidence of these mistakes is likely to be higher than the incidence of false negative mistakes. A group-centred, fairness-based paternalistic policy that excludes PAD for patients with treatment-resistant depression, accordingly, emerges as a compelling, if imperfect, response to the conflicting interests of the affected parties. 


\section{EXTENDING THE ARGUMENT}

Our argument can be applied to the other groups of non-terminally ill patients that we have distinguished. The likelihood and magnitude of false positive mistakes that would accompany extending PAD to young, healthy patients are very great indeed, and the costs to denying them this option are not high. For 'tired of life' patients the issue is less clear-cut. These patients are less likely to misjudge what is in their best interests, and, at least as we have characterised them, they do not suffer from mental illness. There may be, then, a significant number of such patients that would satisfy the decision-making competence and best interests conditions. Opposed to this, however, is the salient fact that such patients do not have an untreatable physical or mental illness. This makes physician involvement in PAD deeply problematic in view of the current social meaning of medicine, which we have argued there are fairness-based reasons to conserve. Additionally, these patients have the option to end their lives by VSED with less concern about whether they do so with decision-making capacity, as compared with patients who suffer from treatment-resistant depression.

Our sense is that a well-considered policy on PAD would not extend this option to 'tired of life' patients. The costs of mistake here are great enough to justify the potential costs imposed on those who are denied the option, especially in light of their having the option of VSED to end their lives. But there is a further and more subtle point to be made about 'tired of life' patients.

Fair paternalism applies to the regulatory scheme that governs PAD, and to the social and self-understandings of those who participate in the practice. Proposals to revise or preserve the social meaning of medicine, or proposals to interpret it one way rather than another, engage larger issues about the fair treatment of different classes of patients. These proposals, moreover, are not advanced in a cultural vacuum. Responsible proposals to revise the social meaning of medicine must recognise the dangers of reinforcing or contributing to undesirable societal attitudes. Tired of life patients frequently express concerns that their lives are no longer valuable, that they have become a burden to others, that their bodies are deformed or that they have no significant contribution to make to their societies. We do not say that such concerns could not be valid. We do contend that they reflect, and are influenced by, wider societal perceptions about the aged.

There is a tendency, at least among those who press to extend the legal option to PAD to more and more populations, to view the decisions of patients to engage in PAD as reflecting nothing more than isolated assessments of the personal value of their own lives. These assessments, and the decisions that they motivate, are neither influenced by wider societal views about the aged nor contribute to these attitudes in any significant way. This kind of individualism is not plausible. No one should dispute that people's attitudes and decisions are deeply influenced by their social environment. Responsible consideration of policies on PAD must consider all the risks involved-direct and indirect, long term and short term. And one risk of extending PAD to tired of life patients is that doing so will contribute to the social devaluation of the elderly.

We are pointing to a potential danger here, not attempting to establish its existence or gauge its severity. Doing so would require its own investigation. Nevertheless, if we are right that there is a genuine concern here, then some caution may be in order. Rather than making it easier for elderly patients to end their lives when they feel they no longer have anything to live for, a humane society, and the medical practice that is a constituent part of it, might do better to combat the social attitudes and social conditions that lead to the self-devaluing attitudes in the first place. True, this course of action might not comfort those tired of life patients who are denied the legal option to PAD. They might feel as if their interests were being sacrificed for the sake of the larger social good. But we have argued that there is not a fundamental right to PAD and that the question of the proper scope of the legal right to PAD is a policy question. And, given that it is a policy question, it is appropriate to take into account all the risks involved.

\section{CONCLUSION}

Our argument supports a conditional policy stance: if PAD is a legal option, it should be limited to the terminally ill. We have paid special attention to patients with treatment-resistant depression and those of advanced age who are tired of life. There are other groups of patients who are not terminally ill and that some may think present as strong or stronger claims for extending PAD beyond terminal illness. We acknowledge that our contention that the legal option to PAD should not be extended to those who are not terminally ill rests on the defeasible assumption that the arguments we have presented can be applied with appropriate modifications to groups of non-terminally ill patients not discussed here.

Considerations of fair paternalism and the social meaning of medicine have less force when directed at PAD for the terminally ill. False positive mistakes for these patients are less serious, as these patients will die soon anyway regardless of medical intervention. Likewise, the threat to the social meaning of medicine is less clear when PAD is confined to the terminally ill. By contrast, permissive policies for PAD that extend beyond terminal illness are likely to open the door to a potentially large number of ethically intolerable cases of false positive mistakes, which would harm vulnerable patients and undermine the professional integrity of physicians. While drawing the line for PAD at terminal illness would preclude some patients from receiving PAD when this arguably would be an ethically permissible option, the severity of such false negative mistakes is substantially mitigated by the option of VSED. Fair paternalism and the social meaning of medicine together make it reasonable to draw the line on a legal option of PAD by limiting it to the terminally ill.

Contributors LAJ, SW and FGM all participated in drafting this manuscript by making substantial contributions to the writing, editing and revising of the manuscript. All authors also made substantial contributions to the design and conception of the manuscript and provided final approval of the completed manuscript. All authors accept accountability for all aspects of the work.

Funding The authors have not declared a specific grant for this research from any funding agency in the public, commercial or not-for-profit sectors.

Competing interests None declared.

Patient consent Not required.

Provenance and peer review Not commissioned; externally peer reviewed.

\section{REFERENCES}

1 Schuklenk U, van de Vathorst S. Treatment-resistant major depressive disorder and assisted dying. J Med Ethics 2015;41:577-83.

2 Steinbock B. Death and depression. Hastings Cent Rep 2017:5:30-42.

3 Miller FG. On changing one's mind in bioethics. Perspect Biol Med 2015;58:507-17.

4 Miller FG. Should a legal option of physician-assisted death include those who are "Tired of Life"? Perspect Biol Med 2016;59:351-63.

5 Miller FG, Appelbaum PS. Physician-assisted death for psychiatric patients - misguided public policy. N Engl J Med 2018;378:883-5.

6 Gert B, Bernat JL, Mogielnicki RP. Distinguishing between patient's refusals and requests. Hastings Cent Rep 1994;24:13-15.

7 Brock DW. Voluntary active euthanasia. Hastings Cent Rep 1992;22:10-22. 
8 van Wijngaarden E, Leget C, Goossensen A. Ready to give up on life: the lived experience of elderly people who feel life is completed and no longer worth living. Soc Sci Med 2015;138:257-64.

9 Bolt EE, Snijdewind MC, Willems DL, et al. Can physicians conceive of performing euthanasia in case of psychiatric disease. dementia or being tired of living? Journal of Medical Ethics 2015;41:592-8.

10 Raijmakers NJ, van der Heide A, Kouwenhoven PS, et al. Assistance in dying for older people without a serious medical condition who have a wish to die: a national crosssectional survey. J Med Ethics 2015;41:145-50.

11 Sagan A. Equal in the presence of death? J Med Ethics 2015;41:584.

12 Sourey D, Papakostas GI, Trivedi MH. Treatment-resistant depression. J Clin Psychiatry 2006:67:16-22.

13 Nelson JC. Managing treatment-resistant major depression. J Clin Psychiatry 2003;64(Suppl 1):5-12.

14 den Hartogh G. Why extra caution is needed in the case of depressed patients. J Med Ethics 2015;41:588-9.

$15 \mathrm{Kim}$ SYH, Lemmens T. Should assisted dying for psychiatric disorders be legalized in Canada? Can Med Assoc J 2016:188:E337-E339.

16 Vandenberghe J. Quoted by M. Cook in bioedge, 2017.

17 Jones DA, Gastmans C, MacKellar C. Euthanasia and assisted suicide: lessons from Belgium. Cambridge, UK: Cambridge University Press, 2017.

18 Vandenberghe J. Physician-assisted suicide and psychiatric illness. N Eng/ J Med 2018;378:885-7.

19 Broome MR, de Cates A. Choosing death in depression: a commentary on 'Treatmentresistant major depressive disorder and assisted dying'. J Med Ethics 2015;41:586-7.

20 Schuklenk U, van de Vathorst S. Treatment-resistant major depressive disorder and assisted dying: response to comments. J Med Ethics 2015;41:589-91.

21 Jansen LA. No safe harbor: the principle of complicity and the practice of voluntary stopping of eating and drinking. J Med Philos 2004:29:61-74.

22 Ivanović N, Büche D, Fringer A. Voluntary stopping of eating and drinking at the end of life - a 'systematic search and review' giving insight into an option of hastening death in capacitated adults at the end of life. BMC Palliat Care 2014;13:1.

23 Wax JW, An AW, Kosier N, et al. Voluntary stopping eating and drinking. J Am Geriatr Soc 2018:66:441-5.
24 Bolt EE, Hagens M, Willems D, et al. Primary care patients hastening death by voluntarily stopping eating and drinking. Ann Fam Med 2015;13:421-8.

25 McGee A, Miller FG. Advice and care for patients who die by voluntarily stopping eating and drinking is not assisted suicide. BMC Med 2017;15:222.

26 Quill TE, Lo B, Brock DW. Palliative options of last resort: a comparison of voluntarily stopping eating and drinking, terminal sedation, physician-assisted suicide, and voluntary active euthanasia. JAMA 1997;278:2099-104.

27 Li M, Watt S, Escaf M, et al. Medical assistance in dying - implementing a hospitalbased program in Canada. N Engl J Med 2017:376:2082-8.

28 Kuznia R. Oregon, searching for a peaceful death: The Washington Post, 2018:3.

29 Pickering Francis L. Assisted suicide: are the elderly a special case? In: Batten M, Rhodes R, Silvers A, Physician-assisted suicide: expanding the debate. UK: Routledge, 1998:75-90.

30 Feinberg J. Harm to self. New York: Oxford University Press, 1986:351.

31 Arneson RJ. Joel Feinberg and the justification of hard paternalism. Legal Theory 2005:11:259-84

32 Onwuteaka-Philipsen B, Legemaate J, van der Heide A, et al. Report on third evaluation of the euthanasia law, 2017. in Dutch, English summary.

33 Pellegrino ED. The internal morality of clinical medicine: a paradigm for the ethics of the helping and healing professions. J Med Philos 2001;26:559-79.

34 Dembo J, Schuklenk U, Reggler J. "For Their own good": a response to popular arguments against permitting Medical Assistance in Dying (MAID) where mental illness is the sole underlying condition. Can J Psychiatry 2018;63:451-6.

35 Arneson R. Paternalism, utility, and fairness. Revue Internationale de Philosophie 1989;43:409-23.

36 Jansen LA, Wall S. Paternalism and fairness in clinical research. Bioethics 2009;23:172-82.

37 Bernat JL, Gert B, Mogielnicki RP. Patient refusal of hydration and nutrition. An alternative to physician-assisted suicide or voluntary active euthanasia. Arch Intern Med 1993;153:2723-31.

38 Quill TE, Ganzini L, Truog RD, et al. Voluntarily stopping eating and drinking among patients with serious advanced illness-clinical, ethical, and legal aspects. JAMA Intern Med 2018;178:123-7. 